\title{
O sentido da educação democrática: revisitando o conceito de experiência educativa em John Dewey
}

\section{Maria Luísa Branco}

Universidade da Beira Interior

\section{Resumo}

A compreensão da atualidade da proposta pedagógica de John Dewey requer uma análise cuidadosa do conceito de experiência educativa desenvolvido por esse autor. Efetivamente, a sua filosofia educativa está alicerçada numa teoria da experiência na medida em que se assenta numa conexão entre a experiência pessoal e a aprendizagem, tendo em vista o alargamento progressivo da primeira. Neste artigo, e com recurso a algumas das principais obras pedagógicas do autor, procedemos à caracterização do conceito de experiência educativa, começando por distingui-lo do conceito de experiência pura e simples. As dimensões fundamentais de qualquer experiência são a continuidade e a interação, distinguindo-se a experiência educativa pela qualidade dessas dimensões no sentido de proporcionar o desenvolvimento do sujeito, isto é, o crescimento e ampliação da sua experiência anterior. A partir da elucidação desse conceito, procuraremos de seguida compreender o impacto que essa concepção possui na organização de um ensino indireto, baseado numa busca cooperativa, e nas concepções de currículo e do papel do professor e do aluno. É ainda tendo em conta a centralidade do conceito de experiência educativa que elucidaremos o nexo profundo existente entre educação progressiva e educação democrática, cuja chave é a realidade social da inteligência potenciada em ambientes democráticos, além do nexo entre educação e democracia.

\section{Palavras-chave}

Educação progressiva - Experiência educativa - Ensino indireto Educação democrática.

\footnotetext{
Correspondência:

Maria Luísa Branco

Universidade da Beira Interior

Depto. de Psicologia e Educação

Estrada do Sineiro, s/n

6200 - Covilhã - Portugal

E-mail: Ibranco@ubi.pt
} 
The meaning of democratic education: revisiting the concept of educative experience in John Dewey

Maria Luísa Branco

Universidade da Beira Interior

\begin{abstract}
Understanding the modernity of Dewey's pedagogical proposal requires a careful appraisal of his concept of educative experience. Actually, his educational philosophy is grounded on a theory of experience, insofar as it rests upon a connection between personal experience and learning whose aim is the progressive enlargement of that experience. In the present article we make use of some of his main pedagogical works to characterize the concept of educative experience, starting with the distinction between educative experience and experience pure and simple. Whilst the fundamental dimensions of any experience are continuity and interaction, the educative experience is distinguished by the quality of these dimensions in promoting the subject's development, that is, the growth and widening of his/her previous experience. After clarifying this concept, we seek to understand its impact for the organization of an indirect teaching based on a cooperative search, and for conceptions of curriculum and the role of pupils and teacher. Still considering the centrality of the concept of educative experience, we try to unveil the deep nexus between progressive education and democratic education, whose key is the social reality of the intelligence heightened by democratic environments, apart from the nexus between education and democracy.
\end{abstract}

\title{
Keywords
}

Progressive education - Educative experience - Indirect teaching Democratic education. 
John Dewey foi um dos líderes da educação progressiva nos Estados Unidos da América no início do século XX, tendo desenvolvido um pensamento educacional equilibrado e sofisticado. Embora reconhecido como um dos grandes intelectuais do século passado e um nome cimeiro da Pedagogia, suas concepções estão muito conotadas com a educação infantil (primeiros anos de vida) e com um conjunto de propostas específicas (trabalho de projeto, aprender fazendo, ensino centrado no aluno) que além de não parecerem muito originais no contexto da educação atual, fruto da sua incorporação pelo pensamento de outros autores e tendências, são frequentemente mal compreendidas (tomadas como fim e não como meio) e desvalorizadas. No texto que se segue, procuraremos aprofundar um conceito central no pensamento educacional do autor, o conceito de experiência educativa e, a partir da reflexão sobre este, visamos esclarecer a profundidade da sua perspectiva, assim como o seu impacto e atualidade na constituição de uma educação para uma sociedade democrática.

\section{A centralidade do conceito de experiência no pensamento pedagógico de John Dewey}

Ao estabelecer a comparação entre educação tradicional e educação progressiva, Dewey (1997) tem o cuidado de acentuar que aquilo que distingue os dois tipos de educação não é, ao contrário do que uma interpretação superficial pode fazer crer, o recurso à experiência. Efetivamente, como relata, "é um grande erro supor, mesmo que tacitamente, que a sala de aula tradicional não era um sítio onde os alunos tivessem experiências" (p. 26), esclarecendo, contudo, que a maioria destas era do "tipo errado" (p. 26). 0 que diferencia a proposta da educação progressiva da educação tradicional não consiste, pois, no recurso à experiência mas na qualidade das experiências proporcionadas. Trata-se, por conseguinte, de uma distinção muito mais profunda, que radica na adoção de Filosofias da Educação diferentes, entendidas como planos distintos para a condução da educação.

O desenvolvimento e a adoção de uma filosofia da educação é especialmente importante no caso da Educação Progressiva, dado que esta, ao invés da anterior, não pode basear-se em tradições consolidadas e institucionalmente consagradas ao longo dos séculos. A proposta que apresenta, para ser eficaz, tem, antes de mais nada, que ser corporizada num novo tipo de organização apoiado em ideias. A sua primeira tarefa, se quer se justificar, é, por conseguinte, desenvolver "uma filosofia da educação baseada numa filosofia da experiência” (p. 29), dado que o que diferencia essa filosofia da educação é uma adequada compreensão do que é a experiência e sua aplicação à educação.

Uma primeira ilação é a de que embora o recurso à experiência seja um dado/postulado importante da Nova Educação (Educação Progressiva), isso não significa, como salienta Dewey (1997), que "todas as experiências sejam genuinamente ou igualmente educativas" (p. 25). 0 que equivale a dizer que conceito de experiência não é sinônimo do conceito de educação, dado que há experiências que não são educativas e outras que podem mesmo ser consideradas deseducativas (mis-educatives). 0 que, por conseguinte, faz com que uma experiência se torne uma experiência educativa? 0 que é que caracteriza uma experiência educativa? A resposta a essa questão afıgura-se tanto mais importante quanto a Educação Progressiva sustenta que a aprendizagem corresponde a um desenvolvimento "dentro, pela e para a experiência” (p. 28), caracterizando-se pelo estabelecimento de uma conexão orgânica entre experiência pessoal e educação, ou seja, pela aplicação do princípio da aprendizagem por meio da experiência pessoal. A concretização da educação progressiva exige, por conseguinte, o desenvolvimento de uma teoria da experiência, subsequente a uma dedução rigorosa de seus princípios e sua posterior aplicação, em termos de "seleção e organização de métodos e materiais educacionais apropriados" (p. 30). 
Enfatizando as raízes biológicas da aprendizagem (esta é essencialmente um processo pelo qual a vida evolui e se mantém), Dewey recorre frequentemente ao termo crescimento (growth) para defınir a educação. 0 crescimento pressupõe imaturidade e esta ao mesmo tempo que se refere à ausência da maturidade comporta a possibilidade de desenvolvimento e de crescimento. 0 imaturo é aquele que ainda não amadureceu mas que possui a capacidade de amadurecer. Nas palavras de Dewey (1997), "tomada em termos absolutos, em vez de comparativos, a imaturidade designa uma força ou capacidade positiva, o poder de crescer" (p. 42).

Essa concepção de imaturidade distanciase da concepção implícita na educação tradicional, para a qual ela representa um estado de menoridade, uma antecipação, consistindo a educação na preparação para as responsabilidades e privilégios da vida adulta, que consiste na "vida verdadeira". Pelo contrário, no pensamento de Dewey, a dependência e a plasticidade associadas à imaturidade no ser humano carecem ser vistas sob uma nova luz. A dependência física em que vive o indivíduo humano durante um período largo da sua vida é acompanhada e compensada por uma capacidade/habilidade excepcional de interação social, que tem de ser aproveitada. Do mesmo modo, a plasticidade, condição do crescimento, pode e deve ser encarada como algo positivo, e não como " a capacidade de mudar de forma de acordo com a pressão externa” (p. 44), mas como correspondendo "essencialmente à capacidade de aprender a partir da experiência" (ibidem). Por conseguinte, o erro da concepção tradicional de educação não reside no focar-se na preparação para o futuro (essa preparação é igualmente inerente à concepção da educação como crescimento, enquanto neste se intersectam o presente e o futuro), mas em ignorar as potencialidades do momento presente como catalisador das energias da aprendizagem. É necessário aproveitar as "forças" que, nas crianças e nos jovens, se centram no presente, aproveitando os estímulos contidos nas situações com as quais os alunos são confrontados, em detrimento do recurso ao adiamento da gratificação ou às penalizações externas, preconizadas pela educação tradicional.

A ligação enunciada entre educação e crescimento, bem como a sua focagem no âmbito atual, facilitam a compreensão do que pode tornar uma experiência deseducativa. Nas palavras de Dewey (1997), uma experiência deseducativa "para ou distorce o crescimento da experiência posterior” (p. 28). Enquadramse, por conseguinte, nessa categoria (por ordem decrescente) as experiências que produzem indiferença; aquelas que inibem a sensibilidade e a capacidade de resposta, comprometendo seriamente a possibilidade de o sujeito vir a ter experiências enriquecedoras no futuro; as experiências que desenvolvem de forma automática uma competência particular do sujeito, estreitando o campo da experiência posterior (especialização precoce); as experiências que, revelando-se em termos imediatos muito agradáveis, contribuem para a formação de atitudes frouxas e descuidadas; e as experiências desconexas que dispersam as energias. 0 aspecto comum a todos estes tipos de experiências deseducativas é, por conseguinte, a ausência de conexão com a experiência posterior, ou seja, a inibição do crescimento.

0 que, então, faz com que uma experiência se torne uma experiência educativa? Uma experiência educativa tem de ser atrativa e não repulsiva mas também não pode ser encarada como um fim em si mesma. Pelo que,

o problema central de uma educação baseada na experiência consiste na seleção do tipo de experiências presentes que persistam de forma frutífera e criativa nas experiências subsequentes. (p. 27-28)

Segundo Dewey (1997), qualquer experiência é caracterizada pela continuidade e pela interação, traduzindo esses aspectos, respectivamente, as suas dimensões longitudinal e lateral. A continuidade refere-se à permeabilidade, na 
medida em que uma experiência se apoia no passado e condiciona o futuro. Toda e qualquer experiência afeta as experiências posteriores, pelas atitudes que condiciona, mas, também, pelo impacto que tem sobre as condições objetivas dessas experiências posteriores. Nesse sentido, a característica da continuidade recolhe a complexidade temporal inerente à experiência. A interação, por sua vez, refere-se às trocas que ocorrem entre o organismo e o meio envolvente. Traduz, por conseguinte, o aspecto espacial daquela. A experiência (sempre feita na primeira pessoa) é, ainda, o resultado de uma combinação peculiar entre um elemento ativo (fazer a experiência) e um elemento passivo ("sofrer" a experiência). Fazer uma experiência implica "sofrer" as consequências dela. Desse modo, embora a atividade e a mudança estejam implícitas na experiência, necessitam ser refletidas para serem consideradas efetivamente experiências.

Voltando à questão: o que faz com que uma experiência se torne uma experiência educativa? podemos responder que é a qualidade da continuidade e da interação alcançadas. Dewey (2002) sustenta que a melhor exemplifıcação do princípio da continuidade consiste no crescimento, pois, numa experiência educativa, a continuidade traduz-se no desenvolvimento que possibilita a prossecução da construção do conhecimento. Como relata em $A$ escola e a sociedade:

0 problema característico dos primeiros anos de escolaridade é, evidentemente, o de aproveitar os impulsos naturais e os instintos da criança e utilizá-los de forma a conduzi-los para um plano mais elevado de percepção e raciocínio, equipada com hábitos mais eficazes; que ela tenha uma consciência mais aprofundada e alargada e um maior controle sobre os poderes da ação. Sempre que este resultado não seja alcançado, a atividade resulta numa mera distração e não num desenvolvimento educativo. (p. 110)

$\mathrm{Na}$ passagem mencionada, o aspecto da interação está implícito na atribuição de uma importância igual aos fatores externos e internos de uma experiência que se pretende educativa. 0 conceito de interação é inseparável do conceito de situação (Dewey, 1997), na medida em que numa experiência é determinante o que ocorre entre o indivíduo e seu ambiente, consistindo isso a situação do indivíduo. Uma situação educativa é, pois, caracterizada por uma adequação entre as características subjetivas do indivíduo e as condições que interagem com aquelas no sentido de as potenciar. Consequentemente, a "continuidade e a interação, na sua ativa união uma com a outra providenciam a medida e o significado educativo de uma experiência” (p. 44-45). Na sua acepção plena, o conceito de experiência é, pois, indissociável do conceito de aprendizagem, enquanto "descoberta das conexões entre as coisas” (p. 139). A aprendizagem pela experiência, entendida desse modo, constitui a condição para o desenvolvimento de uma personalidade completamente equilibrada (que consegue dar sentido/encontrar o fio condutor entre experiências sucessivas, assim como promover a sua inclusão).

A unidade e a integração educativas são duas marcas predominantes do pensamento de Jonh Dewey e remetem-nos diretamente para a sua concepção do currículo. A integração curricular na Laboratory School, dirigida por Dewey entre os anos de 1896-1904, tinha em conta três aspectos essenciais: a própria natureza do conhecimento, a experiência da criança e as exigências de uma sociedade democrática (Tanner, 1997). A realidade é una e a compreensão das conexões que existem entre os diversos campos devem ser acauteladas no delineamento e desenvolvimento do currículo. Da mesma forma também a criança/ jovem deve ser encarada(o) como um ser integrado, que tende a procurar as relações entre a realidade da qual faz parte. 0 objetivo último dessa concepção e de todo o esforço educativo deverá ser, então, a formação do caráter. $\mathrm{Na}$ perspectiva de Dewey (1997), o self não pode nem deve ser entendido como fixo e isolado, algo de constituído a priori, mas como algo que 
se vai formando. Nesse contexto, é fundamental compreender a relação entre self e interesse, que no entender de Dewey constituem apenas “duas designações para o mesmo fato" (p. 352), dado que "o tipo e a quantidade de interesses ativamente prosseguidos numa coisa revelam a qualidade da identidade (selfhood) existente" (p. 352). Dizer que o self se vai constituindo, de uma forma orgânica, por meio da sua relação com a realidade envolvente significa que este se vai alargando e ampliando, pela integração de relações antes desconhecidas e pela apreensão de novos laços na sua experiência. 0 self "virtuoso" consiste naquele que desenvolve as suas capacidades por meio da associação com os outros, constituindo "o interesse em aprender a partir de todos os contatos da vida o interesse moral essencial” (p. 360). Numa escola que pretende habilitar para a vivência numa sociedade democrática, acautelando as suas necessidades, a aprendizagem deve ser organizada de modo a permitir a partilha e o aprofundamento das experiências individuais no sentido anteriormente mencionado.

\section{Implicações do conceito de experiência educativa na organização do processo de ensino-aprendizagem}

A compreensão da experiência como algo de "fluente, embriônico e vital" (Dewey, 2002, p. 163) e constitutivo do self, permite a superação de uma das dualidades características da educação tradicional, a distinção entre a criança e o currículo (a exterioridade do currículo e a mútua estranheza entre o sujeito da aprendizagem e a matéria desta). 0 conjunto de matérias que compõem as disciplinas consiste numa experiência acumulada e, nessa perspectiva, a instrução deverá ser entendida como

a reconstrução contínua, passando da experiência atual da criança para aquela representada pelo corpo organizado de verdades a que chamamos estudos. (p. 163)
0 que está aqui implícito é a reunião dos aspectos psicológico e lógico do conhecimento, que a educação tradicional ignorou, privilegiando o segundo. 0 aspecto psicológico tem em conta que uma matéria de estudo deve relacionar-se com a experiência atual do indivíduo, tomando em consideração sua evolução. Nas palavras de Dewey (2002),

[...] uma descrição psicológica da experiência segue o seu crescimento real, é histórica; regista os passos que foram dados, tanto os inseguros e tortuosos, como os eficientes e bem-sucedidos. (p. 168-169)

0 ponto de vista lógico, pelo contrário, refere-se ao corpo de conhecimentos classificado e sistematizado, assumindo "que o desenvolvimento atingiu um determinado estádio positivo de realização" (p. 169). Esses dois aspectos devem ser encarados como estando inter-relacionados e como sendo ambos necessários. Trata-se efetivamente de, por um lado, privilegiar a experiência pessoal do conhecimento e, por outro, de beneficiar-se da experiência acumulada e sistematizada ao longo de diferentes gerações.

Nessa perspectiva, é possivel afirmar que a criança e o currículo ocupam dois extremos de um mesmo contínuo. 0 currículo (os estudos), ao representar a experiência sistematizada e acumulada possibilita imprimir orientação e direção à experiência da criança, não devendo aqui a orientação ser entendida como imposição externa mas como "libertar o processo de vida no sentido da sua realização mais adequada” (p. 167).

A partir dessa concepção, o centro da aprendizagem desloca-se para o processo, focando-se nas "situações nas quais o estudante necessita do currículo e, consequentemente, está pronto para o explorar, usar e recordar de modo inteligente" (Fishman; McCarthy, 1998, p. 24). Do que decorre a importância e a defesa do ensino indireto, baseado na estruturação de aulas/atividades nas quais os alunos identifiquem problemas e sejam capazes de estabelecer rela- 
ções significativas com as matérias de estudo. Para Dewey, o desenvolvimento dos conceitos relativos a um dado domínio de estudo deve radicar nas atividades das crianças e dos jovens, pelo que uma das principais preocupações dos educadores deverá residir em encontrar as atividades adequadas àquele desígnio. Não deixa, contudo, de ser interessante, assinalar que embora a planificação do ensino-aprendizagem na Laboratory School tivesse em conta os dois aspectos anteriormente mencionados: o ponto de vista do professor e o ponto de vista dos alunos, ou seja, o ponto de vista lógico (organização da matéria) e o ponto de vista psicológico (as atividades dos alunos), era o ponto de vista lógico (os conceitos) que se pretendia ensinar que determinava as atividades a desenvolver e não vice-versa. Como referido por Tanner (1997),

[...] o ponto importante é que os professores começavam com a matéria de estudo e planeavam as atividades das crianças que apelavam a entendimentos progressivamente mais complexos. Eles não começavam com as atividades e tentavam extrapolar ideias a partir do campo de estudo. (p. 48)

Contudo, assim como a aprendizagem, em contexto natural, requer interesse, esforço e direção, do mesmo modo, em contexto escolar, a integração estudante-currículo, marca da aprendizagem autêntica, pressupõe a participação ativa do sujeito. Na sala de aula, como na vida, o aprendente não pode ser considerado passivo e desinteressado, mas ativo e empenhado, pelo que a aprendizagem deve partir de problemas genuínos, que atraiam o interesse dos estudantes e despertem a sua motivação e memória. É nesse sentido que Dewey (2002) compara a mudança introduzida no processo educativo pela educação progressiva a uma revolução copernicana. Esta implica "uma transferência do centro de gravidade", convertendo-se a criança, o estudante, "no Sol em torno do qual gravitam os instrumentos da educação” (p. 40). Não significa isso, contudo, que a educação deva limitar-se a uma satisfação/excitação dos interesses/impulsos manifestados pelo estudante cabendo-lhe, pelo contrário, orientar os impulsos e canalizá-los no sentido da produção de resultados válidos. Como salienta o filósofo,

[...] nada se desenvolve do nada; nada senão imperfeição se pode desenvolver da imperfeição e é certamente isso que acontece quando deixamos a criança a si própria, como uma finalidade e a convidamos a extrair daí novas verdades sobre a natureza ou a conduta (p. 168).

Apesar disso, é ao aluno e não ao professor que cabe investir e cuidar da sua própria aprendizagem.

Subjacente a essa concepção está a importância concedida por Dewey ao lado não cognitivo da aprendizagem. Para além de envolver um aspecto cognitivo, a aprendizagem possui uma vertente emocional e até dramática, na medida em que corresponde à reconciliação das tensões existentes entre o self e o seu contexto, cumprindo uma necessidade vital. A ênfase colocada no processo de aprendizagem traduz-se na importância concedida à inteligência reflexiva, ao desenvolvimento de hábitos de reflexão, que permitam aos indivíduos examinar as suas crenças, testando os seus fundamentos e as suas consequências. Encorajar hábitos reflexivos é promover nos estudantes uma ação com perspectiva, capaz de aumentar o controle dos comportamentos e enriquecer a experiência das coisas e dos acontecimentos, aprofundando o seu significado. É digno de nota o fato de que a construção do pensamento reflexivo pressupõe o desenvolvimento de alguns traços de caráter, nomeadamente, a abertura e a responsabilidade, realçando-se as vertentes cognitiva mas também moral e emocional da inteligência.

0 respeito pelo princípio da continuidade implica, em qualquer situação de ensino-aprendizagem, que se parta da experiência dos alunos, relacionando o objeto de estudo com a continuidade. Nas palavras de Dewey (1997), trata-se de "encontrar o material de aprendizagem dentro 
da experiência” (p. 73). Em seguida, importa promover o desenvolvimento progressivo do que já foi experienciado, no sentido da sua estruturação de forma mais rica e organizada. Novos objetos e conhecimentos devem estar intelectualmente relacionados com as experiências precedentes no sentido de ser proporcionado um progresso na articulação consciente de fatos e ideias.

Se o primeiro passo recomendado é relativamente fácil, o último exige do educador um conhecimento muito grande das matérias e um cuidadoso investimento na preparação das situações de ensino-aprendizagem adequadas. A conjugação dos dois aspectos, na tarefa do educador, complica-se à medida que aumenta a idade dos indivíduos. Como salienta Dewey (1997),

[...] com crianças mais velhas ambos os fatores do problema oferecem dificuldades acrescidas para o educador. É mais difícil encontrar o background da experiência dos indivíduos e mais difícil descobrir como é que os conteúdos já contidos nessa experiência podem ser dirigidos no sentido de conduzir a campos mais largos e [mais bem] organizados. (p. 75)

Ao educador é exigida uma "visão prospectiva”, no sentido de conseguir descortinar, naquilo que já é possuído pelos estudantes, o que pode constituir um instrumento de abertura de novos campos/horizontes, ou seja, o que pode atuar como fonte de novas exigências em termos de poderes de observação e uso inteligente da memória, assegurando a conexão no crescimento intelectual. 0 que Dewey pretende é, pois, que os

professores não apresentem verdades já estabelecidas via exposição, mas que ensinem indiretamente, que estruturem aulas onde eles e os seus alunos identifiquem problemas genuínos e, como resultado, estabeleçam conexões com a matéria do curso. Tomando de empréstimo a terminologia Deweyana, ele quer que os professores ajudem os estudantes a construir as suas próprias continuidades e interações com o currículo. (Fishman; McCarthy, 1998, p. 20)
Cabe aqui uma nota sobre o papel do professor que é, na perspectiva de Dewey, um papel muito exigente. Ao professor é solicitado que conduza as atividades desenvolvidas pelos alunos, monitorizando os seus progressos (0'Brien, 2002). Por isso, como salienta Dewey (1997; 2002), o professor enquanto tal distinguese do acadêmico/cientista, na medida em que

não se deve ocupar com a matéria de estudo em si mesma mas com as interações desta com as capacidades e necessidades presentes dos alunos. (Dewey, 2002, p. 183)

Enquanto que para o acadêmico o problema central é ampliar uma área de conhecimento já sistematizada, identificando e reconduzindo novos problemas a um corpo de verdades estabelecidas, para o professor tratase, prioritariamente, de "induzir uma vivência vital e pessoal" (p. 171). 0 ponto de focagem da atuação do professor não é a matéria de estudo em si mesma e por si mesma mas o encontrar de ligações entre ela e a experiência atual do estudante que possibilite um alargamento efetivo dessa experiência.

Tendo em vista o aspecto psicológico do conhecimento, o professor não pode nem deve ignorar o aspecto lógico, como já foi mencionado. Ele necessita possuir um conhecimento sólido da matéria que leciona a fim de perceber como é que, a partir das necessidades da criança/jovem, o seu conhecimento dessa matéria pode ser dirigido e ampliado. Nesse processo, é fundamental o desenvolvimento das capacidades de observação e de simpatia, dado que o professor deve colocar-se na "retaguarda", o que não significa apagar-se mas manter-se atento à aprendizagem dos seus alunos, preocupando-se em "alimentar os esforços daqueles para resolver criativamente os problemas que encontram no seu dia a dia" (Kosnoki, 2005). Essa "retirada" do professor não deve contudo ser interpretada como um abdicar da autoridade adulta, na medida em que o centrar da educação na experiência pessoal dos alunos acaba por exigir a multiplicação dos contatos 
entre os adultos e as crianças que se envolvem conjuntamente numa busca cooperativa, partilhando conhecimentos. A promoção da busca conjunta e cooperativa do conhecimento acaba por traduzir-se na intensificação e na diversificação dos processos de interação, não só no sentido professor-aluno, como aluno-professor e aluno-aluno (Fishman; McCarthy, 1998).

Em suma, a diversidade de atividades propostas em sala de aula deve ter o propósito de alargar a experiência, consistindo o trabalho do educador em

selecionar aquelas coisas dentro do âmbito da experiência existente que têm a promessa e a potencialidade de apresentar novos problemas, que estimulando novas formas de observação e juizo expandem a área da experiência posterior. (Dewey, 1997, p. 75)

A ampliação da experiência é indissociável do treino da reflexão e do pensamento, na medida em que, ao experienciarmos algo e ao sofrermos as respectivas consequências, nos tornamos capazes de apreender a conexão entre realidades anteriormente percebidas como separadas e que passam a ser percebidas como contínuas. Segundo Dewey (1991), a formação de hábitos reflexivos requer três passos essenciais: 1. estabelecer condições que despertem e guiem a curiosidade; 2. encontrar ligações nas situações experienciadas que favoreçam a sua aplicação em situações posteriores; 3. formular problemas e propósitos que levem o estudante a considerar novas questões e novas perspectivas. A consecução desse propósito exige, por um lado, o conhecimento das características e dos hábitos de cada estudante, pelo professor e, por outro, das condições que rodeiam e afetam a expressão das capacidades individuais, na sala de aula e na escola.

\section{A educação progressiva como educação democrática}

A concepção educativa e pedagógica de John Dewey é marcada por uma visão "profun- damente" democrática, decorrendo igualmente a ligação estabelecida entre democracia e educação da análise do conceito de experiência. Democrata convicto, Dewey (2005) subscreve uma concepção maximalista de democracia, defendendo que

esta é mais do que uma forma de governo ou de governança; é, acima de tudo, uma forma de vida associativa, de uma experiência humana construída em conjunto. (p. 35)

E enquanto forma de vida é, simultaneamente, individual e social, apelando

à participação de cada ser humano maduro na formação dos valores que regulam a vida dos homens em conjunto: o que é necessário do ponto de vista quer do bem social geral, quer do pleno desenvolvimento dos seres humanos como indivíduos. (Dewey, 1939a, p. 400)

0 fundamento dessa pretensão consiste na asserção básica de que "todos os que são afetados pelas instituições sociais devem ter uma quota parte na sua produção e condução" (p. 401). Desse modo, os alicerces da democracia radicam na fé na inteligência humana e nas possibilidades abertas pela experiência cooperativa no aprofundar da democracia. Esta surge como um experimento, que radica no exercício de uma inteligência social, não constituindo um fim em si mesma mas um meio que possibilita o aprofundar da natureza humana. 0 objetivo de uma politica democrática é, por conseguinte, "criar um ambiente social que tenda a enriquecer a experiência de todos, e a trazer ao ser instituições que continuamente impulsionem o desenvolvimento da personalidade de cada um" (Chanial, 2002, p. 73), considerando que o respeito pela liberdade individual e pela dignidade humana é tributário de uma experiência de maior qualidade (Dewey, 1997). A liberdade individual é entendida pelo autor como correspondendo, essencialmente, à liberdade de espírito (freedom of mind), traduzida em quatro liberdades fundamentais (e 
que são as liberdades consagradas na Bill of Rights norte-americana): a liberdade de crença e consciência; a liberdade de expressão; a liberdade de reunião para diálogo e discussão; e a liberdade de imprensa (Dewey, 1939a). Sem o assegurar destas, não há lugar para a libertação da inteligência que em democracia deve enformar a ação, ficando os indivíduos tolhidos no seu desenvolvimento e a sociedade privada dos seus contributos. Por sua vez, a igualdade de oportunidades implicada no entendimento da democracia como experiência cooperativa assenta no princípio de que cada indivíduo pode contribuir para o todo social, independentemente da sua posição ou função na sociedade.

Em suma, para Dewey (2005), as sociedades democráticas assentam, por um lado, na possibilidade de libertação das capacidades individuais e, por outro, na diversidade de inquietações comuns partilhadas. 0 ideal democrático alimenta-se, simultaneamente, da importância do desenvolvimento das capacidades individuais aliada ao desenvolvimento da consciência de que estas devem ser colocadas a serviço de projetos comuns. Efetivamente, a confiança no reconhecimento de interesses mútuos como fator de controle social, isto é, o perspectivar da possibilidade de mudança e reajustamento contínuo de hábitos, fruto da interação livre entre os vários grupos sociais, é um aspecto crucial da vivência democrática. 0 significado da promoção da ação conjunta (com a derrubada das várias barreiras que a podem obstaculizar, tais como as barreiras sociais, étnicas e de nacionalidade) é, em última análise, uma forma de potenciar a compreensão plena do significado da atividade individual, e de assegurar a aplicação/potenciação dos princípios da continuidade e da interação. A primeira traduz-se na capacidade de dar seguimento e reformular as ações individuais mediante um trabalho cooperativo e a segunda na multiplicação dos canais de comunicação e na diversificação dos âmbitos de relação que enriquecem aquela ação.

0 interesse particular das sociedades democráticas na educação decorre das caracterís- ticas mencionadas. Como salienta Dewey (2005), “após uma maior individualização e perante 0 aparecimento de uma comunidade de interesses mais vasta, o essencial passa por um esforço deliberado na sua manutenção e pelo seu desenvolvimento" (p. 35), que depende da educação. Esta deve estar particularmente atenta à realidade aberta e colegial da inteligência, cujo florescimento requer pontos de vista diversos assim como o acesso de todos aos recursos culturais e às esferas do discurso público. 0 desenvolvimento da inteligência requer, desse modo, ambientes favorecedores da integridade moral e da interação cooperativa, marcas da educação progressiva, promovendo "o crescimento dos interesses pessoais no sentido de um 'interesse no público' em geral e uma maior simpatia pelos concidadãos” (Kosnoski, 2005, p. 657).

Assim como as estruturas democráticas possibilitam uma experiência humana mais rica do que as autocráticas, também a educação progressiva está orientada para a ampliação da experiência humana. A educação progressiva é, na sua essência, uma educação democrática. Embora considerando que todas as instituições sociais são educativas, em sentido lato, na medida em que influenciam a formação de hábitos e atitudes, Dewey (1939b) destaca a importância da escola na medida em que, juntamente com a família, "influencia diretamente a formação e o crescimento de atitudes e disposições, emocionais, intelectuais e morais” (p. 717). Desse modo, não é indiferente se o processo educativo é conduzido de forma democrática ou não, pelas consequências que isso tem em termos da formação de interesses e na condução das atividades no seio da sociedade envolvente. A adoção de métodos democráticos é fundamental na construção de uma sociedade alicerçada em hábitos democráticos de pensamento e ação, sem o que a democracia corre o risco de corresponder a uma fórmula esvaziada de conteúdo (reforçando-se com essa recomendação a ideia da democracia como forma de vida). Considerando que a não adoção de métodos democráticos equivale a um “desperdício educacional” (p. 721), 
o filósofo salienta a importância de integrar as escolas na vida social e de estas assumirem consciente e responsavelmente o seu papel de instituições determinantes na confıguração da ordem social futura.

Com esse objetivo, sustenta que a escola deve consistir numa sociedade em miniatura, organizando-se como uma comunidade embrionária. Segundo Dewey (2002),

uma sociedade é um conjunto de pessoas unidas por estarem a trabalhar de acordo com linhas comuns, animadas dum espírito comum e com referência a objetivos comuns. (p. 24)

A organização da aprendizagem em torno de atividades, como preconizado pela educação progressiva, e da resolução de problemas suscitada por essas atividades, conduz a uma assinalável alteração no ambiente escolar, que se traduz num incentivo natural à assistência mútua, como forma de cooperação e associação, ao contrário do que se passava no registo da educação tradicional, marcada por um elevado grau de individualismo e de competição. Como resultado

um espírito de livre comunicação, de troca de ideias, sugestões, resultados de experiências anteriores bem ou mal sucedidas, torna-se a nota dominante das aulas. (p. 25)

Assiste-se, assim, a uma renovação da escola, que passa a estar organizada numa verdadeira base social, proporcionando aos estudantes vivências democráticas, com consequências na manutenção e renovação do sistema social mais lato. Um aspecto fundamental dessa concepção é a ênfase colocada na educação escolar como libertação das possibilidades do espírito humano e no fortalecimento da organização social, em detrimento de meros objetivos utilitários ou economicistas.

\section{Considerações finais}

A teoria educativa de John Dewey baseia-se numa concepção da natureza humana marcada pela plasticidade e pela abertura. 0 ser humano é entendido fundamentalmente como interação, sendo as relações sociais determinantes na constituição do sentido do self. 0 autor alerta-nos, pois, para a importância educativa dos contextos e, nesse sentido, para o primado da comunidade sobre o indivíduo (Glassman, 2001). 0 desenvolvimento da individualidade de cada um corresponde a um alargamento progressivo da experiência, que, sendo pessoal, fundeia na experiência social. A ampliação da experiência é também o objetivo primordial da educação, sem a qual esta verdadeiramente não acontece, e cuja consecução requer ambientes e instituições apropriadas, leia-se cooperativos e democráticos.

Nesse contexto, o valor das instituições e dos ambientes democráticos reside na possibilidade que encerram de reconstrução e enriquecimento da experiência humana. 0 sentido da democracia é profundamente educativo na medida em que a sua tarefa principal consiste em "criar de modo perpétuo uma experiência mais livre e humana da qual todos participem e para a qual contribuam" (Chanial, 2002, p. 176), entendendo-se a expressão da diferença como uma forma de alargar a experiência de cada um.

Contudo, a equação estabelecida por Dewey entre sociedade e comunidade, assim como a identificação da democracia como estando alicerçada em grupos sociais cooperativos, não está isenta de críticas. Para Singer (1985 apud Gambôa, 2004), essa associação entre sociedade e comunidade exclui do âmbito social um conjunto de interações importantes, nomeadamente as relações de conflito e de competição, erigindo, ainda, como critério exclusivo de sociabilidade a democracia entendida de forma corporativa. Segundo Gambôa (2004), a concepção de Dewey resulta de um equilíbrio precário e dificilmente alcançável entre o fomentar da "diversidade de interesses" e a "unidade na partilha”. Para outros autores, a visão de democracia proposta pelo autor possui muito de utópico, sendo possível questionar até que ponto constitui uma proposta viável na atual sociedade capitalista, atravessada por flagrantes desigualdades e dominada 
por um ideal de consumismo (Teitelbaum; Apple, 2001). Em contrapartida, Puckett, Harkavy e Benson (2007) realçam a atualidade do seu pensamento na constituição de uma cultura democrática, em oposição à concepção formal de democracia dominante. Controvérsias à parte, o ideal democrático, tal como expresso no pensamento de Dewey, afigura-se-nos como um poderoso ideal orientador e como um aliado do Humanismo, na medida em que se baseia na afırmação do potencial criativo do ser humano, que pretende desenvolver até ao limite, sendo indissociável da ideia de uma educação permanente.

\section{Referências bibliográficas}

CHANIAL, P. Is the democratic ideal conceivable without the notion of human nature? On John Dewey's democratic humanism. Diogenes, v. 49/3, n. 195, p. 71-76, 2002.

DEWEY, J. The modes of societal life. In: RATNER, J. Intelligence in the modern world: John Dewey's philosophy. New York: Random House, 1939a. p. 365-404.

The schools and the social welfare. In: RATNER, J. Intelligence in the modern world: John Dewey's philosophy. New York: Random House, 1939b. p. 638-728.

How we think. New York: Prometheus Books, 1991.

Democracy and education. New York: Simon \& Schuster, 1997.

A escola e a sociedade: a criança e o currículo. Lisboa: Relógio D’Água, 2002.

A concepção democrática de educação. Viseu: Pretexto, 2005.

FISHMAN, S. M.; MCCARTHY, L. John Dewey and the classroom practice. New York: Teachers College Press, 1998.

GAMBÔA, R. Educação, ética e democracia: a reconstrução da modernidade em John Dewey. Porto: Asa, 2004.

GLASSMAN, M. Dewey and Vygotsky: society, experience and inquiry in educational practice. Educational Researcher, v. 30, n. 3, p. 3-14, maio 2001.

KOSNOKI, J. Artful discussion: John Dewey's classroom as a model of deliberative association. Political Theory, v. 33, n. 5, out. p. $654-677,2005$.

O'BRIEN, L. A response to "Dewey and Vygotsky: society, experience, and inquiry in educational practice". Educational Researcher, v. 31, n. 5, p. 21-23, jun./jul. 2002.

PUCKETT, J.; HARKAVY, I.; BENSON, L. Dewey's dream: universities and democracy in an age of education reform. Philadelphia: Temple University Press, 2007.

SINGER, B. Dewey's concept of community - a critique. Journal of the History of Philosophy, v. 23, n. 4, p. 555-569, 1985.

TANNER, L. Dewey’s laboratory school: lessons for today. New York: Teachers College Press, 1997.

TEITELBAUM, K.; APPLE, M. John Dewey. Currículo sem Fronteiras, v. 1, n. 2, p. 194-201, jul./dez. 2001.

Recebido em 28.08.09

Aprovado em 01.02.10

Maria Luísa Branco é licenciada em Filosofia pela Universidade Católica Portuguesa (UCP) de Lisboa, onde completou também 0 Mestrado em Ciências da Educação. Doutorou-se em Educação pela Universidade da Beira Interior (UBI), Covilhã, onde leciona desde 1997. É atualmente Professora Auxiliar, com nomeação definitiva, no Departamento de Psicologia e Educação da UBI e pesquisadora do Instituto de Filosofia Prática sediado na mesma universidade. Suas pesquisas têm privilegiado as áreas do Pensamento Pedagógico Contemporâneo, Educação para os Valores, Educação para uma Cidadania Democrática e Educação Intercultural. 